\title{
AN AUTOPSY CASE OF COXSACKIE VIRUS B 4 MYOCARDITIS WITH INTERSTITIAL NEPHRITIS AND HEPATITIS
}

\author{
YASUO OHKITA, KENSUKE YAMADA, HIRONORI TOSHIMA \\ AND NOBORU KIMURA \\ Third Department of Internal Medicine, \\ Kurume University School of Medicine, \\ Kurume, 830, Japan
}

\author{
AKIRA TANIMURA AND TERUYUKI NAKASHIMA \\ Second Department of Pathology, Kurume University \\ School of Medicine, Kurume, 830, Japan \\ HIDEAKI CHIBANA AND MASAHISA SHINGU \\ Department of Virology, Kurume University \\ School of Medicine, Kurume 830, Japan
}

(Received for publication January 25, 1977)

\begin{abstract}
An autopsy case with Coxsackie $\mathrm{B}_{4}$ viral myocarditis associated with interstitial nephritis and hepatitis is presented. Electrocardiograms demonstrated significant ST elevation, complete A-V block (causing syncopal attacks), and subsequent deep QS pattern, which were simulated acute myocardial infarction. Autopsy findings revealed extensive myocardial destruction including the conduction system with inflammatory mononuclear cell infiltration. In addition to cardiac damage, persistent renal failure and high transaminase level suggested renal and hapatic involvements by viral infection, which were comfirmed at postmortem examination.
\end{abstract}

\section{INTRODUCTION}

It is generally appreciated that Coxsackie virus group B can produce acute myocarditis and pericarditis. Detailed reports were presented by Smith (1970), and by Sainai et al. (1968). They pointed out that the most popular electrocardiographic changes were nonspecific ST-T changes. This report descriebs an autopsy case of Coxsackie $\mathrm{B}_{4}$ viral infection with extensive myocardial damage and unusual electrocardiographic features, associated with renal and hepatic involvements.

\section{CASE REPORT}

A 24-year-old woman was admitted to our hospital on July 20, 1974, with 
syncopal attacks and fever. She had been in good health until 5 days previously, when she had genaral fatigue and high fever $\left(39^{\circ} \mathrm{C}\right)$. She was in bed at her home and could not take any food because of nausea. She felt weak and slight dyspneic. Feverishness continued until July 19, when she took examination by her home doctor. Her blood pressure was $86 / 60 \mathrm{mmHg}$ and electrocardiogram (Fig. 1) showed significant ST elevation in leads $V_{1}$ through $V_{3}$. She was admitted to a hospital with a clinical diagnosis of acute myocardial infraction. She felt well transiently, but then developed syncopal attacks with convulsive movements for 1-2 minutes. Complete A-V block with heart rate of $24 / \mathrm{min}$. was seen in electrocardiogram (Fig.1). She was trans-

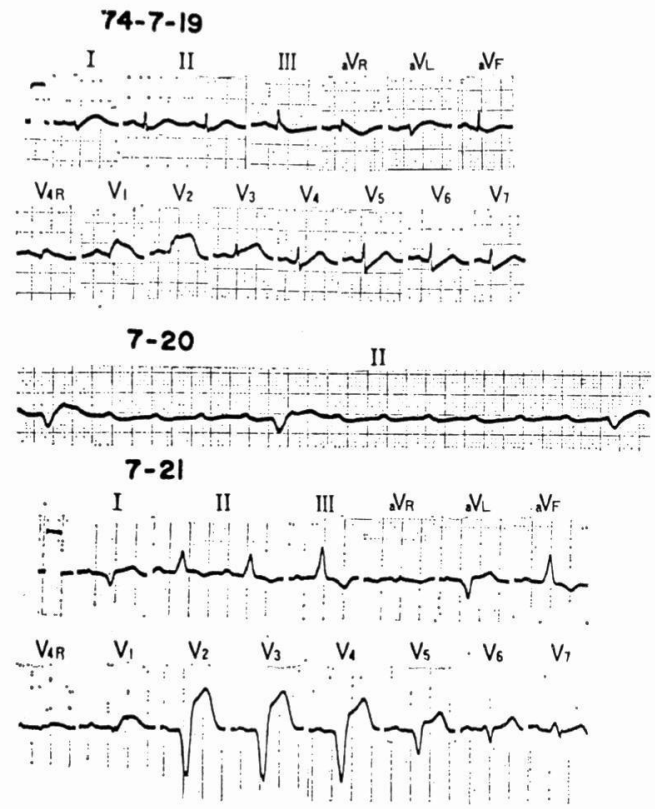

Fig. 1 The ECG shows ST-T changes at first. The rhythm changes to complete A-V block on July 20. There are deep $Q$ waves in many leads on July 21, simulating to anterior and lateral myocardial infarction. ferred to our hospital emergently on July 20, 1974. There was no history of previous cardiac, hepatic, and renal disease. No specific family history.

Physical examination showed a acutely ill, pale, and drowsic woman. Her pulse was $30 / \mathrm{min}$. with an irregular rhythm, the temperature $39^{\circ} \mathrm{C}$ and the respiration $24 / \mathrm{min}$. Her blood pressure was $72 / 48 \mathrm{mmHg}$. There was no scleral icterus. Cervical vein dilatation was present. Heart sounds were distant and the forth sound was heard as gallop rhythm. No heart murmur or friction rub was andible. Moist rales were noted at both lower lobes. Neither hepatomegaly nor splenomegaly was detected.

The results of laboratory findings are summarized in Fig. 2. The whitecell counts was $14,7000 / \mathrm{mm}^{3}$ with a

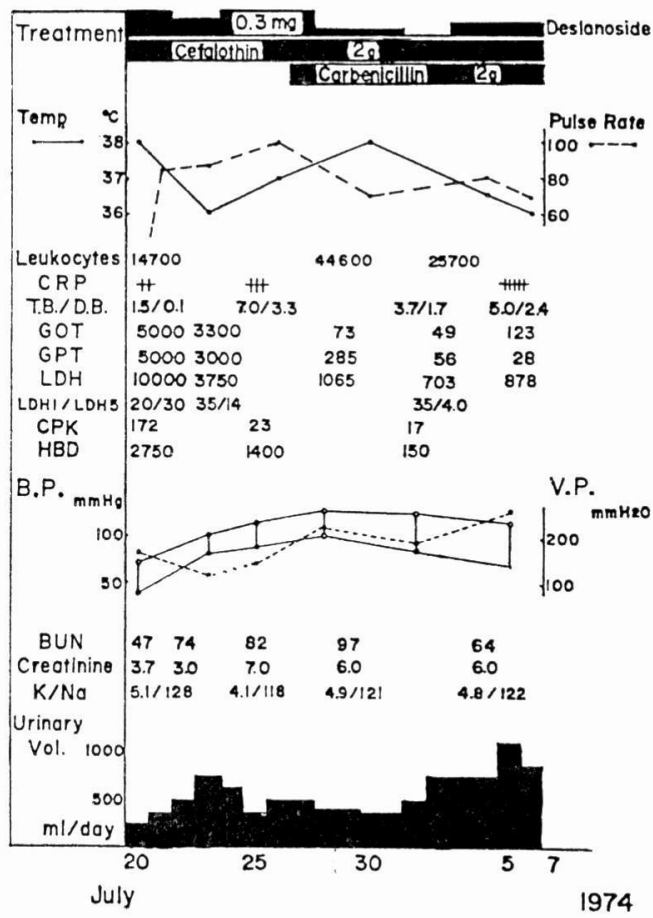

Fig. 2 Clinical course at the hospital. 
normal differential counts, the hematocrit $41 \%$, and the hemoglobin 15.9 $\mathrm{g} / 100 \mathrm{ml}$. Venous pressure was $170 \mathrm{~mm}$ $\mathrm{H}_{2} \mathrm{O}$ and circulation time from arm to tongue was 48 seconds. Urine tests revealed moderate protein and sugar. In the urine sediments, there were many red blood cells, a few white blood cell casts and hyaline casts in the highpower field. Serum glutamine-oxaloacetic-transaminase (GOT) was over 5,000 units, and lactate dehydrogenase (LDH) was over 10,000 units. Immediately after admission, we performed artificial transvenous right ventricular pacing as her electrocardiogram showed complete $\mathrm{A}-\mathrm{V}$ block with ventricular rate of 30 beats/min. On July 21, electrocardiogram (Fig. 1) showed sinus rhythm with right axis deviation suggesting left posterior hemiblock, deep $\mathrm{Q}$ waves in leads $V_{2}$ through $V_{5}$, $S T$ elevation in leads $V_{1}$ through $V_{5}$, and $T$ wave inversion in leads II, III, aVF. The patient had no syncopal attack after artificial pacing but continued to complain of dyspnea. The blood pressure was $80 / 50 \mathrm{mmHg}$. The urine volume was $250 \mathrm{ml}$ for the first hospital day. Proteinuria and hematuria persisted with a spacific gravity of 1010 to 1015 . Blood urea nitrogen, creatinine, and potassium showed progressive increasings. Peritoneal dialysis was started from July 22. Patient still complained of nausea and could not take any fluid or food per os. Complete bed rest was continued. Clinical course at our hospital was summarized in Fig. 2. Adequate fluids, furosemide, deslanoside, and cefalothin were given intravenously. In spite of these treatments, hypotension with high central venous pressure continued. On the other hand, jaundice became remarkable with high bilirubinemia. Liver function tests revealed hepatocellular damage with high serum emzymes. The liver edge became palpable and its maximal size reached $10 \mathrm{~cm}$ on right midclavicular line. Clinical and chemical jaundice subsided gradually, but dyspnea became worse. Moist rales were heard at both lower lobes and third sound gallop became audible at the apex. On chest roentgenogram, pleural effusion was found at the right lower chest. There were many grampositive diplococci in her sputum with remarkable leukocytes. The patient became drowsic especially in the evening with occasional clonic spasms at the end of July and died from respiratory failure on August 7 (19th day).

Serum neutralizing antibodies to group B Coxsackie virus were checked twice (Table 1). The seventh day serum showed an antibody titer of 1:80 against $\mathrm{B}_{4}$; the fifteenth day serum showed a titer of $1: 320$. This fourfold rise supported strongly acute infection of Coxsackie virus $B_{4}$.

TABLE 1

Neutralizing antibodies to group $B$ Coxsackie virus

\begin{tabular}{cl|c|c} 
& & 7 th. day & 15 th. day \\
\hline Cox. & $\mathrm{B}_{1}$ & $1: 80$ & $1: 80$ \\
$\mathrm{~B}_{2}$ & $<1: 10$ & $<1: 10$ \\
$\mathrm{~B}_{3}$ & $1: 80$ & $1: 80$ \\
$\mathrm{~B}_{4}$ & $1: 80$ & $1: 320$ \\
$\mathrm{~B}_{5}$ & $<1: 10$ & $<1: 10$ \\
$\mathrm{~B}_{6}$ & $1: 10$ & $1: 20$ \\
\hline
\end{tabular}

Autopsy was performed approximately 6 hours after death. The heart (weight 400 grams) was hypertrophic and dilated. There were many necrotic spots on the septal area. The valves were grossly normal. No mural thrombus was noted, neither coronary occulusion nor stenosis. The myocardium (Fig. 3) showed areas of extensive in- 
flammatory mononuclear cell infiltration, mainly lymphocytes and a few plasma cells with myocardial cell dropout and diffuse necrosis. There was no replacement by area of fibrosis. The endocardium and epicardium were also infiltrated with mononuclear cells.

With careful examination of the conduction system, the atrioventricular node, His bundle, and right bundle showed areas of moderate inflammatory cell infiltration with edematous change in the interstitial area. Left bundle was completely degenerated, necrotic, and discontinued due to inflammation. The kidneys showed necrosis on both papillary areas. There was no specific changes in glomeruli. Tubuli were degenerated and dilated. Chronic mononuclear inflammatory cells were seen within the interstitial space (Fig. 4). The liver (weight 1050 grams) was congestive, degenerative, and fibrotic. There was mild bile stasis without bile cannaliculi dilatations. The parenchymal cells were diffusely necrotic and showed fibrotic changes between the central areas (Fig. 5). There were inflammatory mononuclear cells in the areas of necrosis with hyperlasia of Kupffer cells. The lungs were damaged by severe bacterial infection. There was white abscess at the right upper lobe. Exudates with many polymorphonuclear leucocytes were seen in the alveoli on all lobes. Severe brochopneumonia was present.

\section{DISCUSSION}

This patient showed acute cardiac, renal and hepatic illness following antecedent respiratory infection. Autopsy findings demonstrated necrotic changes with inflammatory mononuclear cell infiltration in the myocardium, the renal interstitial space, and the hepatic

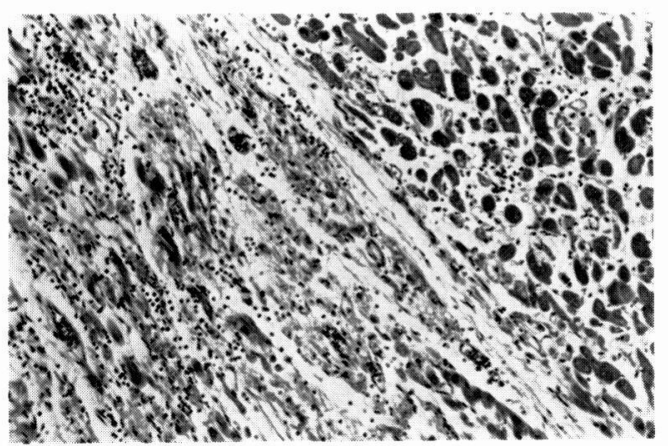

Fig. 3 Photomicrograph of a section of ventricular myocardium. Note the area of imflammatory cell infiltration and myocardial cell dropout with necrosis.

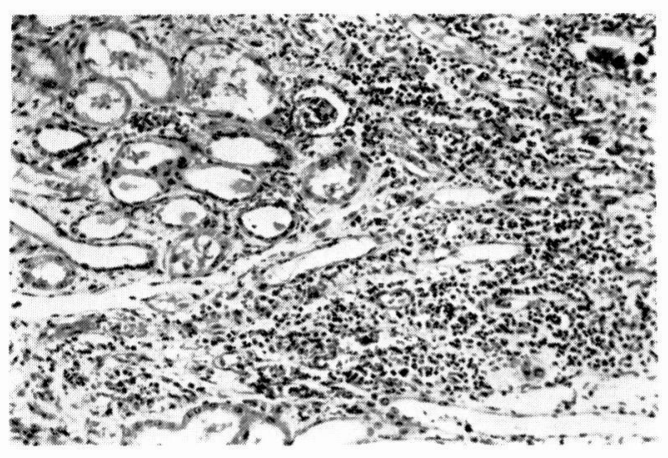

Fig. 4 Photomicrograph of a section of kidney showing a area of interstitial nephritis.

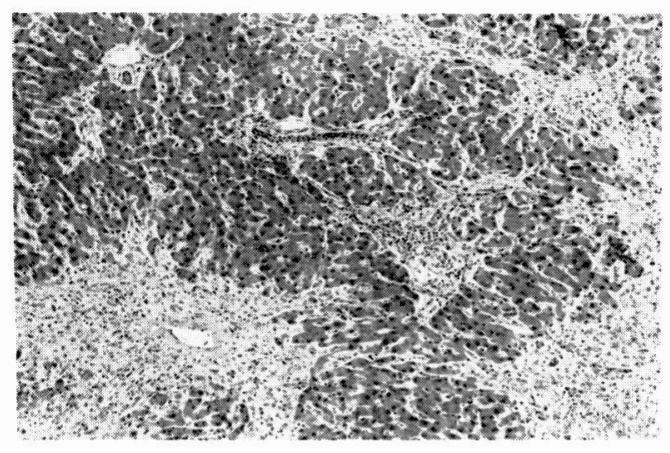

Fig. 5 Photomicrograph of a section of liver. Parenchymal cells show necrotic and fibrotic changes. Note the area of inflammatory cell infiltration. 
parenchyma. Examination of serum neutralizing antibodies comfirmed Coxsackie virus $\mathrm{B}_{4}$ infection. Consequently, this case was diagnosed as Coxsackie $\mathrm{B}_{4}$ viral myocarditis with interstitial nephritis and hepatitis.

It is generally appreciated that the most popular electrocardiographic changes in viral myocarditis are the nonspecific ST-T changes, although variable abnormalities have been reported. For instance. Toshima et al. (1976) described that non-specific ST-T changes $(85 \%)$, low voltage (35\%), abnormal $\mathrm{Q}$ wave $(30 \%)$, bundle branch block $(25 \%)$ sinus tachycardia (20\%), and complete $\mathrm{A}-\mathrm{V}$ block (15\%) were noticed among 20 cases of acute viral myocarditis and pericatditis. Deep Q-wave pattern with loss of $R$ waves following ST elevation seemed unusual in viral myocarditis and simulated the changes of acute myocardial infarction. Tavel and Fisch (1964) reported two cases of myocarditis with QS pattern simulating myocardial infarction and they concluded that diffuse myocardial destruction or relacement could give such an electrocardiographic pattern. Autopsy findings of this case also revealed extensive myocardial destruction with inflammatory cell infiltration. The coronary arteries were normal. Therefore, we concluded that deep Q-wave pattern in this case was due to myocardial destruction from viral infection.

Incidence of severe conduction disturbances has been reported to be relatively rare in viral myocarditis. For example, Sainani et al. (1968) reported only one case with second degree A-V block among 22 cases and Smith et al. (1970) decribed two cases with complete A-V block among 42 cases. However, we have already experienced 3 cases with complete $\mathrm{A}-\mathrm{V}$ block among 20 cases, in 2 of them conduction disturbance was a major defect. In this case, on ne- cropsy, many mononuclear inflammatory cells infiltrated in the conduction system, and left bundle was completely degenerated, necrotic, and discontinued. Therefore, the conduction system seems to be one of the susceptive structure to viral infection and it seems necessary to pay more attention on viral myocarditis as a cause of severe conduction disturbances or Adams-Stokes attack.

The other important point is the additional evidence of widespread organ involvements as seen in this case clinically and pathologically. There was a possibility that acute renal failure in this case was due to low renal blood flow from cardiogenic shock. However, urinary casts continued for many days, and urinary osmotic pressures remained low. On autopsy, many mononuclear inflammatory cells infiltrated in the interstitial space of the kidneys.

Burch and Colcolough (1969) reported the case of viral panmyocarditis associated with nephritis due to Coxsackie virus $\mathrm{B}_{4}$. He concluded Coxsackie virus $\mathrm{B}_{4}$ could produce acute and chronic glomerulonephritis and interstitial nephritis. The remarkable high values of serum emzymes on admission were other characteristic points in this case. These high values might also be supposed due to myocardial damage and/or liver congestion from cardiogenic shock. However, postmortem examination revealed marked mononuclear inflammatory cell infiltration with lobular necrosis in addition to congestion in the liver. Therefore, Coxsackie $\mathrm{B}_{4}$ viral infection seemed to play a significant role in the hepatic damage, causing high serum enzyme levels in the case. Sum and Smith (1966) also reported the pathological evidence of hepatitis due to infection with Coxsackie virus group $B$. Heart, kidney, and liver tissue are excellent culture media for most viruses. Whereas Coxsackie B viruses are well 
known to have cardiotrophic properties, it seems likely that Coxsackie B viruses can involve the liver and the kidney as well as the heart.

\section{REFERENCES}

Burch, C. E. and Colcolough, H. L. (1969). Progressive Coxsackie viral pancarditis and nephritis. Ann. Intern. Med., 71, 963-970.

LERNER, A. M. and Wilson, F.M. (1973). Virus myocardiopathy. Progr. Med. Virol., 15, 63-91.
Sainani, G.S., Krompotic, E. and Slodki, S. J. (1968). Adult heart disease due to the Coxsackie virus B infection. Medicine, 47, 133-147.

Smith, W.G. (1970). Coxsackie B myopericarditis in adults. Am. Heart J., 80, 34-46.

Sun, N.C. and Smith, V.M. (1966). Hepatitis associated with myocarditis. New Engl. J. Med., 274, 190-193.

TAveL, M. E. and Fisch, C. (1964). Abnormal $\mathrm{Q}$ waves simulating myocardial infarction in diffuse myocardial diseases. Am. Heart J., 69, 534-537.

Toshima, H., Yamada, $\mathrm{K}$. and Chibana, $\mathrm{H}$. (1976). Viral myocarditis. Respiration and Circulation, 24, 105-112. 